Thorax (1976), 31, 771.

\title{
Fragile lung in the Marfan syndrome
}

\author{
J.A. M c M. TURNER and N. N. STANLEY \\ Cardiothoracic Department, The Central Middlesex Hospital, London NW10 7NS and \\ Department of Medicine, The Middlesex Hospital, London WIN $8 A A$
}

\begin{abstract}
Turner, J. A. McM. and Stanley, N. N. (1976). Thorax, 31, 771-775. Fragile lung in the Marfan syndrome. Two cases of the Marfan syndrome presented with spontaneous pneumothorax. Both had chest radiographs showing bilateral bullae in the upper lung zones and pulmonary function tests consistent with mild emphysema. There were decreases in forced expiratory flow rates at low lung volumes, carbon monoxide transfer factor, and lung elastic recoil. It is suggested that pneumothorax and bullous emphysema in this syndrome are caused by a weakness in the pulmonary connective tissue framework.
\end{abstract}

The Marfan syndrome is a hereditary disorder with well-known skeletal, cardiovascular, and ocular manifestations. Some of these can be attributed to congenital dysplasia (for example, dolichostenomelia) whereas others are acquired due to a weakness of connective tissue (for example, hyperextensible joints, redundant ligaments, kyphoscoliosis, and aortic aneurysm). Diverse abnormalities may occur in the lung, but although not infrequent they are much less familiar. The following two cases are presented since they illustrate that the syndrome is a cause of spontaneous pneumothorax and that this respiratory complication sometimes provides its mode of presentation. Respiratory function tests done after recovery also shed some further light on the mechanical properties of the lung in this connective tissue disorder.

\section{METHODS}

Forced expiratory volume in one second $\left(\mathrm{FEV}_{1}\right)$, vital capacity (FVC), and peak flow rate (PFR) were measured using a differentiating spirometer (Ohio 840), and flow-volume curves during maximum forced expirations were displayed on a storage oscilloscope (Tektronex, Type 564B) and recorded by Polaroid photography. Total lung capacity (TLC), functional residual capacity (FRC), and residual volume (RV) were determined by the helium dilution method. The transfer factor for carbon monoxide (TF) and the transfer coefficient (KCO) were measured using the single-breath method of Ogilvie et al. (1957). The static elastic recoil pressure of the lungs (Pst(1)) was measured by the oesophageal balloon technique (Milic-Emili et al., 1964) at several points during expiration in the upper half of the lung volume range, and the static deflation pressurevolume curves were plotted.

For comparison, flow volume curves were measured also in eight healthy non-smokers who were similar to the patients in age, sex, and length of trunk. Normal values for lung volumes and carbon monoxide transfer were obtained from Cotes (1975) and for Pst(1) from Turner, Mead, and Wohl (1968) in relation to a corrected standing height based on the length of the trunk. The normal ratio between the crown-pubis and pubis-sole measurements in Caucasians is 0.92 (McKusick, 1972) and this factor was used to correct the excessive contribution of the lower extremities to the total height.

\section{CASE REPORTS}

CASE 1 (A.M.) This 29-year old man was admitted to the Central Middlesex Hospital in February 1974 complaining of dyspnoea and chest pain for three days. He had smoked 10 cigarettes daily for approximately 10 years but had no previous respiratory symptoms. A diagnosis of neurofibromatosis had been made at the National Hospital for Nervous Diseases in 1964 and confirmed histologically after the excision of a painful cutaneous nodule at the Royal Infirmary, Edinburgh in 1971. His father, both paternal uncles, and his only brother and sister were tall and slim in build. 
He was $191 \mathrm{~cm}$ in height (crown-pubis/pubis-heel ratio 0.83) with an arm span of $196 \mathrm{~cm}$ and weighed $62 \mathrm{~kg}$. Arachnodactyly, high-arched palate, hypermobile joints, bilateral subluxation of the lenses, café-au-lait spots, and subcutaneous nodules were obvious features. The cardiovascular system was normal, but there were clinical and radiographic signs of a large left-sided pneumothorax. This was aspirated by means of an intercostal catheter connected to an underwater seal and he made an uneventful recovery. A subsequent chest radiograph showed that the lungs were fully expanded, but there were bilateral apical bullae.

CASE 2 (J.M.) A 30-year-old man was admitted to the Central Middlesex Hospital in May 1975 due to a sudden onset of chest pain and breathlessness while at work. Two years earlier he had been admitted to another hospital with a left-sided spontaneous pneumothorax but had otherwise enjoyed good health. He had never smoked. His father had died when 46 years old due to a ruptured aortic aneurysm. On physical examination he was $183 \mathrm{~cm}$ in height (crown-pubis/pubis-sole ratio 0.84 ) with an arm span of $188 \mathrm{~cm}$ and weighed $62 \mathrm{~kg}$. There was arachnodactyly, hypermobility of the joints, iridonesis, and a high degree of myopia. The cardiovascular system was normal. The chest radiograph showed a small right-sided pneumothorax, which resolved spontaneously over the next week. Small bullae were seen in the upper zones of both lungs in a later radiograph.

\section{RESPIRATORY FUNCTION TESTS}

These were performed after a follow-up period of 15 months in A.M. and of six weeks in J.M. during which there had been no recurrence of pneumothorax. The results are given in the Table.

T A B L E

RESPIRATORY FUNCTION TESTS

\begin{tabular}{|c|c|c|}
\hline & $\begin{array}{l}\text { Case } 1 \\
\text { A.M. }\end{array}$ & $\begin{array}{c}\text { Case } 2 \\
\text { J.M. }\end{array}$ \\
\hline 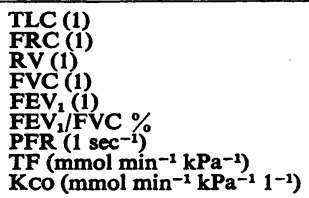 & $\begin{array}{c}8 \cdot 9(123) \\
4 \cdot 9(121) \\
2 \cdot 3(121) \\
6 \cdot 6(127) \\
5 \cdot 0(119) \\
75 \\
11 \cdot 1(106) \\
7 \cdot 7(66) \\
0 \cdot 86(48)\end{array}$ & $\begin{array}{c}8 \cdot 3(124) \\
4 \cdot 7(118) \\
2 \cdot 5(139) \\
5 \cdot 8(121) \\
4 \cdot 4(110) \\
76 \\
12 \cdot 2(121) \\
8 \cdot 3(75) \\
1 \cdot 00(56)\end{array}$ \\
\hline
\end{tabular}

Observed values as \% predicted are given in parentheses.
The intrathoracic gas volumes and FVC were greater than predicted normal values. The $\mathrm{FEV}_{1}$ was also increased, but only in proportion to the FVC since the $\mathrm{FEV}_{1} / \mathrm{FVC}$ ratio was normal. Although the PFR was normal, the maximum expiratory flow-volume curves in both patients showed a marked reduction in flow rate at low lung volumes (see Fig. 1), even though J.M. had never smoked and A.M. had stopped the habit after his pneumothorax the year before. A gas exchange defect was indicated by decreases in both TF and Kco. There was a reduction in lung elastic recoil, which is shown by the static deflation pressure-volume curves in Figure 2.

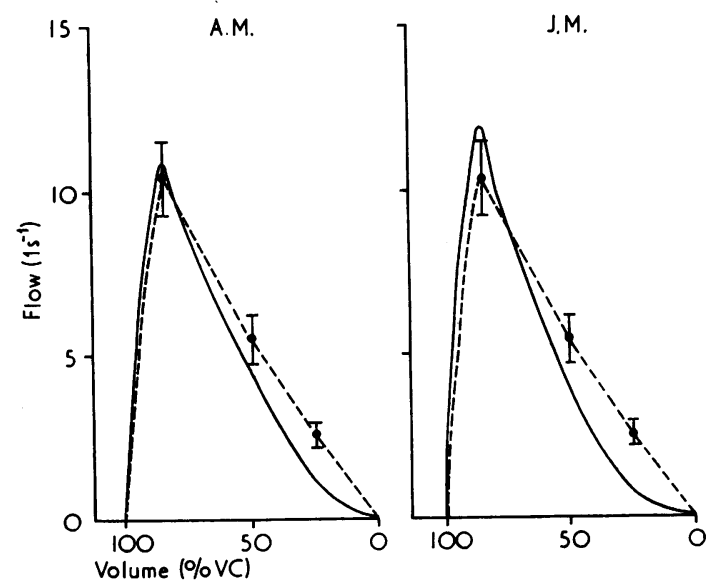

FIG. 1. Maximum expiratory flow-volume curves. Expiratory flow rate is plotted against volume (expressed as \% VC) for the two patients (continuous lines). Also shown for comparison is an interrupted. line linking mean values ( $\pm S D$ ) of peak flow ando maximum flow rates at $50 \%$ and $25 \%$ of $V C$ in eight healthy controls.

\section{DISCUSSION}

The Marfan syndrome was diagnosed in both $N$ patients by its characteristic skeletal and ocular features associated with a suggestive familyo history. Neurofibromatosis was an interestingo finding in A.M. since it has not been mentioned as a feature in a recent review of the Marfan? syndrome (McKusick, 1972). However, the coexistence of the two conditions has been reportede in one other individual (Witwicki and Kutrzebski 1974). 


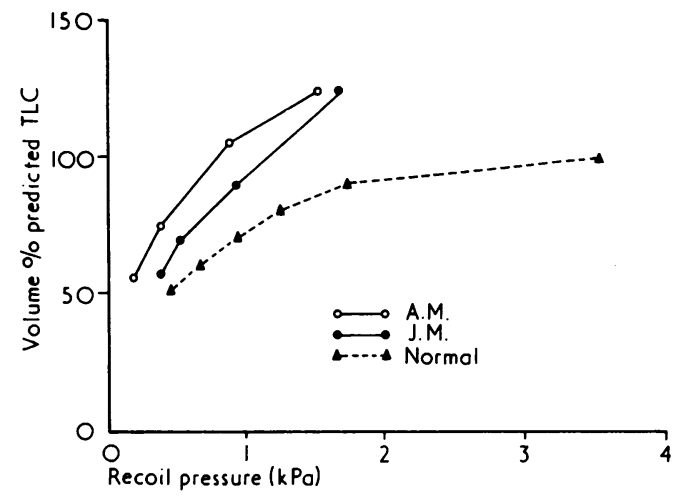

FIG. 2. Static deflation pressure-volume curves. Lung volume expressed as \% predicted TLC is plotted against lung recoil pressure. Compared with the normal data of Turner et al. (1968), the patients' curves are displaced to the left due to diminished lung elastic recoil.

The commonest respiratory complications are spontaneous pneumothorax and generalized emphysema (Dwyer and Troncale, 1965). Bullae have of ten been observed in cases with emphysema and have sometimes provided an obvious cause of pneumothorax (Bolande and Tucker, 1964; Leménager et al., 1968). Histological examination may reveal fragmentation of the pulmonary connective tissue fibres (Reye and Bale, 1973). There have also been reports of cystic disease (Oswald and Parkinson, 1949), pulmonary malformations (Van Buchem, 1958), bronchiectasis (Katz, 1952) and an increased susceptibility to pneumonia (Green and Emerson, 1943). Chest wall deformities include pectus excavatum and carinatum (Wilner and Finby, 1964). Some degree of kyphoscoliosis occurs in $50 \%$ of cases (Robins, Moe, and Winter, 1975) and may be sufficiently severe to cause cor pulmonale due to respiratory failure (Wanderman, Goldstein, and Faber, 1975).

In their literature survey, Dwyer and Troncale (1965) noted that some type of pulmonary disorder occurred in $10 \%$ of patients with the Marfan syndrome. One-third of these were due to spontaneous pneumothorax, which suggests an incidence rate one hundred times higher than in normal populations (Cran and Rumball, 1967). As a corollary of this predisposition to pleural rupture, it has been suggested that the frequency of tall stature in otherwise normal young men with recurrent simple pneumothorax may sometimes represent a forme fruste of the Marfan syndrome
(Forgacs, 1969). An important clinical point is that the acute chest pain and breathlessness of pneumothorax should not be confused with aortic dissection, which is the commonest cause of death in the syndrome (Murdoch et al., 1972).

Pulmonary function tests have been reported in only a few cases of the Marfan syndrome and have usually been limited in scope. No major abnormalities have been found by routine spirometry in those with normal chest radiographs. However, airways resistance was increased during expiration at low lung volumes in four out of seven cases in one study (Fuleihan, Suh, and Shepard, 1963), in keeping with the present observation of diminished flow rate in the latter part of forced expiration. Lung elastic recoil and TF were also reduced in another young man who presented with spontaneous pneumothorax (Breslin, 1973). Likewise, the average TF was only $8.2 \mathrm{mmol} \mathrm{min}^{-1}$ $\mathrm{kPa}^{-1}$ in a group of five young adults (Chisholm, Cherniack, and Carton, 1968) and was even lower in the patients reported by Fuleihan et al. (1963), although they included some adolescents. While arterial oxygen saturation has usually been normal at rest, it may fall on exercise (Katz, 1952; Dwyer and Troncale, 1965). That the loss of elastic recoil in our cases was accompanied by increased lung volumes has not been a regular finding. The discrepancy may be explained by chest wall restriction caused by kyphoscoliosis or pectus excavatum in some cases (Dwyer and Troncale, 1965; Lipton, Greenwald, and Seriff, 1971) or use of standing height to predict normal test values. Lung volumes were also increased in other studies (Fuleihan et al., 1963; Chisholm et al., 1968) when assessed in comparison with sitting height. There was no chest wall or spinal deformity in our two patients, and the height was corrected for the disproportionate length of their extremities.

Although histological information was lacking, several points indicate that our patients had a mild degree of emphysema underlying their history of pneumothorax. In the absence of focal fibro-inflammatory disease of the lungs or pleura, pneumothorax is usually due to the rupture of subpleural emphysematous blebs, and both patients had radiographic evidence of bullae in the upper lung fields. The overall pattern of their lung function tests was consistent with a disorder of the peripheral gas-exchanging part of the lung. Loss of elastic recoil, which has the function of holding the airways open, or the presence of communicating bullae may be a sufficient explanation for the reduced forced expiratory flow rate at low lung 
volumes without invoking an intrinsic abnormality of the tracheobronchial tree. Furthermore, bullous emphysema has been observed in previously reported cases of pneumothorax occurring in the Marfan syndrome, as cited above.

Several biochemical observations may be relevant in the pathogenesis of spontaneous pneumothorax and emphysema in the syndrome. Skin collagen is abnormally soluble in vitro (Laitinen et al., 1968) and an increased urinary excretion of hydroxyproline suggests that collagen is more rapidly degraded in vivo (Sjoerdsma et al., 1958). Also noteworthy is the preferential distribution of lesions to tissues with high collagen contents (for example, the fibrous root of the aorta, ligaments, tendons, and bones). More than $10 \%$ of the lung's dry weight consists of collagen (Pierce and Hocott, 1960) and its function, as in other organs (Harkness, 1961), is to maintain structural integrity by virtue of its great tensile strength (Pierce and Ebert, 1965). If normal collagen synthesis is inhibited in experimental animals, the lungs are very friable and the alveolar walls and pleura may be ruptured by only moderate mechanical stress (Stanley et al., 1975). It is therefore proposed that pneumothorax and emphysema in the Marfan syndrome are further manifestations of the generalized connective tissue abiotrophy, perhaps due to a molecular defect in collagen, and that involvement of lung tissue renders it less able to withstand the wear and tear of everyday life.

We are grateful to Dr. Martin McNicol for permission to report the patients under his care, and to $\mathrm{Dr}$. Michael Rudolf and Dr. Brian Harrison for providing data on normal flow-volume locps. Dr. J. A. McM. Turner is in receipt of a Sir Jules Thorn Research Fellowship.

\section{REFERENCES}

Bolande, R. P. and Tucker, A. S. (1964). Pulmonary emphysema and other cardiorespiratory lesions as part of the Marfan abiotrophy. Pediatrics, 33, 356.

Breslin, A. B. X. (1973). Recurrent pneumothorax in a patient with the Marfan syndrome. Medical Journal of Australia, 1, 1191.

Van Buchem, F. S. P. (1958). Cardiovascular disease in arachnodactyly. Acta Medica Scandinavica, 161, 197.

Chisholm, J. C., Cherniack, N. S., and Carton, R. W. (1968). Results of pulmonary function testing in 5 persons with the Marfan syndrome. Journal of Laboratory and Clinical Medicine, 71, 25.
Cotes, J. E. (1975). Lung Function, 3rd edition. Blackwell, Oxford.

Cran, I. R. and Rumball, C. A. (1967). Survey of spontaneous pneumothoraces in the Royal Air Force. Thorax, 22, 462.

Dwyer, E. M., Jr. and Troncale, F. (1965). Spontaneous pneumothorax and pulmonary disease in the Marfan syndrome. Annals of Internal Medicine, 62, 1285.

Forgacs, P. (1969). Stature in simple pneumothorax. Guy's Hospital Reports, 118, 199.

Fuleihan, F. J. D., Suh, S. K., and Shepard, R. H. (1963). Some aspects of pulmonary function in the Marfan syndrome. Bulletin of the Johns Hopkins Hospital, 113, 320.

Green, H. and Emerson, P. W. (1943). Arachnodactylia. Archives of Pediatrics, 60, 299.

Harkness, R. D. (1961). Biological functions of collagen. Biological Review, 36, 399.

Katz, H. L. (1952). Thoracic manifestation in Marfan's syndrome (arachnodactyly). Quarterly Bulletin of Sea View Hospital, 13, 95.

Laitinen, O., Uitto, J., Iivanainen, M., Hannuksela, M., and Kivirikko, K. I. (1968). Collagen metabolism of the skin in Marfan's syndrome. Clinica Chimica Acta, 21, 321.

Leménager, J., Renault, P., Neel, J. P., and Feutry, J. P. (1968). Les accidents respiratoires de la maladie de Marfan (A propos d'une observation de pneumothorax par rupture de bulle emphysémateuse). Journal Français de Médecine et Chirurgie Thoraciques, 22, 438.

Lipton, R. A., Greenwald, R. A., and Seriff, N. S. (1971). Pneumothorax and bilateral honeycombed lung in Marfan syndrome. American Review of Respiratory Disease, 104, 924.

McKusick, V. A. (1972). Heritable Disorders of Connective Tissue, 4th edition, pp. 61-223. C. V. Mosby, Saint Louis.

Milic-Emili, J., Mead, J., Turner, J. M., and Glauser, E. M. (1964). Improved technique for estimating pleural pressure from esophageal balloons. Journal of Applied Physiology, 19, 207.

Murdoch, J. L., Walker, B. A., Halpern, B. L., ३ Kuzma, J. W., and McKusick, V. A. (1972). Life 을 expectancy and cause of death in the Marfan syndrome. New England Journal of Medicine, 286, 804.

Ogilvie, C. M., Forster, R. E., Blakemore, W. S., and N Morton, J. W. (1957). A standardized breath holding technique for the clinical measurement $N$ of the diffusing capacity of the lung for carbon $N$ monoxide. Journal of Clinical Investigation, 36, 1.

Oswald, N. and Parkinson, T. (1949). Honeycomb lungs. Quarterly Journal of Medicine, 18, 1.

Pierce, J. A. and Ebert, R. V. (1965). Fibrous network $\stackrel{\oplus}{\oplus}$ of the lung and its change with age. Thorax, 20, 469.

Pierce, J. A. and Hocott, J. B. (1960). Studies on the collagen and elastin content of the human lung. Journal of Clinical Investigation, 39, 8. 
Reye, R. D. K. and Bale, P. M. (1973). Elastic tissue in pulmonary emphysema in Marfan syndrome. Archives of Pathology, 96, 427.

Robins, P. R., Moe, J. H., and Winter, R. B. (1975). Scoliosis in Marfan's syndrome. Journal of Bone and Joint Surgery, 57-A, 358.

Sjoerdsma, A., Davidson, J. D., Udenfriend, S., and Mitoma, C. (1958). Increased excretion of hydroxyproline in Marfan's syndrome. Lancet, 2, 994.

Stanley, N. N., Alper, R., Cunningham, E. L., Cherniack, N. S., and Kefalides, N. A. (1975). Effects of a molecular change in collagen on lung structure and mechanical function. Journal of Clinical Investigation, 55, 1195.

Turner, J. M., Mead, J., and Wohl, M. E. (1968). Elasticity of human lungs in relation to age. Journal of Applied Physiology, 25, 664.
Wanderman, K. L., Goldstein, M. S., and Faber, J. (1975). Cor pulmonale secondary to severe kyphoscoliosis in Marfan's syndrome. (Letter). Chest, 67, 250.

Wilner, H. L. and Finby, N. (1964). Skeletal manifestations in the Marfan syndrome. Journal of the American Medical Association, 187, 490.

Witwicki, T. and Kutrzebski, A. (1974). Marfan's syndrome and neurofibromatosis in the same patient. (Polish). Wiadomosci Lekarskie, 27, 561.

Requests for reprints to: Dr. J. A. McM. Turner, Department of Medicine, The Middlesex Hospital, Mortimer Street, London W1N 8AA. 